how doctors and families will use the information and how best to present it. The first indications are that in multiple endocrine neoplasia type 2 there will be little demand for antenatal diagnosis because of the low morbidity of the condition and the availability of biochemical screening leading to effective surgical treatment. Children predicted to carry the gene will probably be selected for earlier and more careful biochemical screening. What is not clear is how accurate the test must be before the clinician and the family are happy for biochemical screening to be discontinued if the prediction is negative.

Director,

Cancer Research Campaign Human Cancer Genetics Research Group, University of Cambridge, Cambridge CB2 1QP
1 Thakker RV. Ponder BAJ Multiple endocrine neoplasia, Baillieres Clin Endocrinol Metab 1988:2:1031-67.

Mathew CGP, Chin KS, Easton DF, et al. A linked genetic marker for multiple endocrine neoplasia type 2 a on chromosome 10. Nature 1987;328:527-8.

Simpson NE, Kidd KK, Goodfellow PN, et al. Assignment of multiple endocrine neoplasia type $2 \mathrm{~A}$ to chromosome 10 by linkage. Nature 1987;328:528-30.

4 Jackson CE, Norum RA, O'Neal LW, Nickolai TF, Delaney JP'. Linkage between MEN 2B and chromosome 10 markers linked to MEN 2A. Am f Hum Genet 1988:43:A147.

Noll WW, Bowden DW, Maurer LH, et al. Genetic mapping of familial medullary carcinoma of the thyroid/multiple endocrine neoplasia type $2 \mathrm{~A}$ with polymorphic loci on chromosome $10 . \mathrm{Am} f$ Hum (ienet 1988;43:A29.

$6 \mathrm{WH}$ J. Goodfellow PN, Giuffra I.A, at al. Fibronectin receptor beta subunit locus: DNA polymorphisms and linkage mapping studies based on non-CEPH families. Cytogenet Cell Genet $1989 \cdot 51: 1110-1$.

7 Nakamura Y, Mathew CGP, Sobol $\mathrm{H}$, et al. Linked markers flánking the gene for multiple endocrine neoplasia type $2 \mathrm{~A}$. (ienomics 1989:5:199-203.

8 Benham F, Hart K, Crolla J, Bobrow M, Francavilla M, Goodfellow PN. A method for generating hybrids containing non-selected fragments of human chromosomes. Genomics 1989;4:509-17. elenius H, Mathew CGP, Nakamura Y, et al. Application of linked DNA markers to screening families with multiple endocrine neoplasia type 2 A. Eur J Surg Oncol (in press).

0 Sobol H, Nared SA, Nakamura $Y$, et al. Screening for multiple endocrine neoplasia type $2 \mathrm{~A}$ with DNA-polymorphism analysis. N Engl f Med 1989;321:996-1001.

\title{
Bulimia nervosa
}

\section{Antidepressant or cognitive therapy is effective}

The eating disorder bulimia nervosa was first described 10 years ago. ${ }^{1}$ Since then more than 50 studies of its prevalence have been conducted and there have been over 20 controlled treatment trials. With a decade of research behind us, it seems timely to consider what has been learnt.

Initially the criteria used to diagnose the disorder were very different in North America and in Britain. ${ }^{2}$ These differences largely disappeared in 1987 with the introduction in the United States of the DSM-III-R definition, ${ }^{3}$ which was broadly similar to the more restrictive criteria already in use in Britain. The initial differences undoubtedly contributed, however, to the divergent views that were held over the character, prevalence, and treatment of the disorder.

It is now agreed that bulimia nervosa has three key features. ${ }^{12}$ Firstly, there is loss of control over eating with recurrent episodes of bulimia. Typically these episodes of overeating occur in secret and are a source of shame and self disgust. Secondly, there are extreme attempts to control shape and weight; these include self induced vomiting, strict dieting, and the misuse of purgatives and diuretics. Thirdly, there are disturbed attitudes to shape and weight, which resemble those found in anorexia nervosa. These attitudes are central to the psychopathlogy of the disorder ${ }^{2}$ and have been described as "a morbid fear of becoming fat"' or a "persistent overconcern with shape and weight." "Commonly associated clinical features include a high level of general psychiatric symptoms, particularly those associated with depressive disorders, and impaired social functioning.

The physical features of bulimia nervosa have been less extensively studied than those of anorexia nervosa. The most common physical symptoms are fatigue, feeling "bloated," "puffy cheeks," irregular or absent menstruation, and toothache. ${ }^{+5}$ Few abnormalities tend to be found on examination, and body weight is usually within the normal range. Occasionally the salivary glands, particularly the parotid glands, are enlarged, and this accounts for some complaints of facial swelling. ${ }^{67}$ The pathophysiology of this hypertrophy is unclear. In those patients who have vomited frequently for some years there may be erosion of the dental enamel, especially of the ligual surfaces of the teeth. ${ }^{8}$ This accounts for most complaints of toothache. In addition, some patients who have repeatedly induced vomiting by using their fingers to stimulate the gag reflex have a characteristic distribution of calluses on the dorsum of the hand.
Various abnormalities may be found on laboratory testing. About half the patients have electrolyte disturbance, the most common abnormalities being hypochloraemia, hypokalaemia, hyponatraemia, and a raised bicarbonate concentration. ${ }^{9}$ Very occasionally these abnormalities are life threatening. They result from the self induced vomiting and the misuse of purgatives and diuretics. The nature of the disturbance depends on the predominant behaviour: vomiting is associated with metabolic alkalosis, whereas metabolic acidosis is characteristic of purgative misuse. Another abnormality sometimes found on laboratory testing is a raised serum amylase activity, ${ }^{10}$ usually with high activities of both isoenzymes. The explanation for this increase is unclear. With the exception of severe electrolyte disturbance, none of these physical abnormalities merits direct intervention: most resolve rapidly in response to treatment directed at the eating disorder itself.

The diagnostic status of bulimia nervosa has been the subject of much debate. Is it a discrete psychiatric syndrome or a variant of another psychiatric disorder? Some authors have argued that bulimia nervosa is closely related to major depressive disorder." This view is difficult to sustain in the light of the mounting evidence of differences between the disorders in phenomenology, distribution, familial transmission, biological correlates, and course. ${ }^{12}$ Others have emphasised the association with substance abuse and "borderline personality disorder," ${ }_{1+}$ but these associations are found in only a few patients. ${ }^{15} 16$ The disorder with which there is undoubtedly a close relation is anorexia nervosa. ${ }^{2}$ Bulimia nervosa and anorexia nervosa have very similar clinical features, and between a third and a half of patients with bulimia nervosa have met strict diagnostic criteria for anorexia nervosa in the past, while many others have almost, but not quite, met these criteria. ${ }^{17} \mathrm{~A}$ case may be made for viewing anorexia nervosa and bulimia nervosa as different expressions of a single psychiatric disorder ${ }^{2}$; but until data are available that allow the prognostic and therapeutic implications of the two diagnoses to be compared (thereby testing their predictive validity) it seems premature either to amalgamate the two diagnostic concepts or to give one diagnosis precedence over the other. This is the position taken in DSM-III-R, ${ }^{3}$ and as a result some patients are eligible for both diagnoses - namely, those who are both seriously underweight and have episodes of bulimia. 
Like anorexia nervosa, bulimia nervosa mainly affects white women in Western societies. Most patients present when they are in their 20s, though their history of disturbed eating usually stretches back into adolescence. Typically the breakdown of control over eating is preceded by a period of extreme dieting and loss of weight. Views on the prevalence of the disorder among the group most at risk-adolescent girls and young women-have varied over the years, but with improved methods of case definition and detection most studies now give a rate of around $1 \cdot 0 \% .^{18-20}$ This figure should not be accepted uncritically, however, as consistency must not be confused with accuracy: the studies could all be subject to equivalent sources of error. ${ }^{21}$ Also unclear is the extent to which the cases detected in community surveys resemble those seen in clinics. The few longitudinal studies of community samples have found that bulimic symptomatology varies over time with only a few subjects showing the persistent severe disturbance that characterises clinical cases. ${ }^{22-24}$

Views on the treatment of bulimia nervosa are continuing to evolve. In the United States, but not in Britain, psychiatrists have shown enthusiasm for the use of antidepressant drugs, and controlled trials have shown that these drugs are more effective than placebo in reducing the frequency of overeating and the intensity of some of the other symptoms of the disorder. ${ }^{25}{ }^{26}$ Interestingly, antidepressant drugs are equally effective whether or not the patient is depressed, ${ }^{272}$ suggesting that the decrease in bulimic symptoms might not be the result of their antidepressant action. Instead, it could be the expression of a direct effect of these drugs on the brain mechanisms that control eating. Another possibility is that the anxiolytic effects of antidepressant drugs help patients resist the urge to overeat, at least in the short term. ${ }^{28}$ Two further points about the effectiveness of these drugs are important. Firstly, there is no evidence that they affect the patients' disturbed attitudes to shape and weight or their extreme attempts to diet. ${ }^{29}{ }^{30}$ Secondly, there have been no studies of the maintenance of change after treatment with antidepressant drugs, and the one anecdotal report was far from encouraging. ${ }^{31}$ Until it has been shown that antidepressant drugs have more than a selective and transitory effect, their place in the treatment of bulimia nervosa must be questioned.

The main alternative approach to treatment is a specific form of short term psychotherapy. This treatment is based upon the cognitive view of the disorder, namely that the characteristic attitudes to shape and weight of patients with bulimia nervosa are of primary importance in maintaining the condition. The treatment, a form of cognitive behaviour therapy, is designed not just to change the patients' behaviour but also to modify the disturbed attitudes to shape and weight. ${ }^{32}$ It has been evaluated in a series of controlled trials, and the results suggest that the immediate effects of treatment compare favourably with those obtained with antidepressant drugs, with there being a substantial improvement in both eating habits and attitudes to shape and weight. ${ }^{334}{ }^{34}$ Psychosocial functioning in general also improves. Significantly, these changes seem to be maintained for at least the first year after treatment. ${ }^{35}{ }^{36}$ Several direct comparisons of antidepressant drugs and cognitive behaviour therapy are currently under way. The short term results of one of these studies are available: group cognitive behaviour therapy was found to be more effective than treatment with the antidepressant drug imipramine, and adding imipramine to group cognitive behaviour therapy did not significantly improve outcome..$^{37}$

This decade of research on bulimia nervosa has seen developments that are also relevant to the understanding and treatment of other eating problems. For example, the cognitive view of bulimia nervosa applies equally well to anorexia nervosa $^{38}$ and, with certain modifications, the cognitive behavioural treatment for bulimia nervosa may be applied to patients with that disorder.$^{39}$ Interest in evaluating treatments for bulimia nervosa has led to a more precise characterisation of the behavioural and cognitive disturbances seen in these patients and to the development of more refined assessment techniques. ${ }^{+0+1}$ These techniques could be applied to studies of the clinical features and treatment of other eating disorders. It is to be hoped that over the next 10 years the intense interest of researchers in bulimia nervosa and its treatment will extend to the sister condition, anorexia nervosa, and to other related eating and weight problems.

CHRISTOPHER G FAIRBURN

Wellcome Trust Senior Lecturer,

University Department of Psychiatry,

Warneford Hospital,

Oxford OX3 7JX

I Russell GFM. Bulimia nervosa: an ominous variant of anorexia nervosa. Psychol Med 1979;9:429 48.

Fairburn CG, Garner DM. The diagnosis of bulimia nervosa. International foumal of Eating Disorders 1986;5:403-19.

3 American Psychiatric Association. Diagnostic and statistical manual of mental disorders. 3rd ed. Revised. (DSM-III-R). Washington, DC: American Psychiatric Association, 1987.

4 Abraham SF, Beumont PJV. How patients describe bulimia or binge-eating. Psychol Med 1982;12:625-35

5 Mitchell JE, Hatsukami D, Eckert ED, Pyle RL. Characteristics of 275 patients with bulimia. Am f Psychiatry 1985;142:482-5.

6 Levin PA, Falko J, Dixon K, Gallup EM, Saunders W. Benign parotid enlargement in bulimia. Ann Intern Med 1980;93:827-9.

Burke RC. Bulimia and parotid enlargement - case report and treatment. F Otolaryngol 1986;15:4951 .

8 Simmons MS, Grayden SK, Mitchell JE. The need for psychiatric-dental liaison in the treatment of bulimia. Am f Psychiatry 1986;143:783-4.

Mitchell JE, Pyle RL, Eckert ED, Hatsukami D, Lentz R. Electrolyte and other physiological abnormalities in patients with bulimia. Psychol Med 1983;13:273-8.

10 Gwirtsman HE, Kaye WH, George DT, Carosella NW, Greene RC, Jimerson DC. Hyperamylasemia and its relationship to binge-purge episodes: development of a clinically relevant amylasemia and its relationship to binge-purge ep
laboratory test. $f$ Clin Psychiatry 1989;50:196-204.

11 Pope HG Hudson JI. New hope for binge eaters. New York: Harper and Row, 1984.

11 Pope HG Hudson J1. New hope for binge eaters. New York: Harper and Row, 1984. Strober M, Katz JL. Do eating disorders and affective disorders share a com
dissenting opinion. International foumal of Eating Disorders 1987;6:171-80.

13 Levy AB, Dixon KN, Stern SL. How are depression and bulimia related? Am $\mathcal{Y}$ Psychiatry 1989;146: 162-9.

14 Lacey $\mathrm{JH}$, Evans $\mathrm{CDH}$. The impulusivist: a multi-impulsive personality disorder. $\mathrm{Br} \mathcal{F}$ Addict 1986;81:641-9.

15 Turnbull J, Freeman CPL, Barry F, Henderson A. The clinical characteristics of bulimic women International foumal of Eating Disorders 1989;8:399-409.

16 Pope HG, Frankenburg FR, Hudson JI, Jones YM, Yurgelun-Todd D. Is bulimia associated with borderline personality disorder? A controlled study. $\mathcal{F}$ Clin Psychiatry 1987;48:181-4

17 Russell GFM. The diagnostic formulation in bulimia nervosa. In: Garner DM, Garfinkel PE, eds Diagnostic issues in anorexia nervosa and bulimia nervosa. New York: Brunner/Mazel, 1988:3-25.

King MB. Eating disorders in general practice. Br Med f 1986;293:1412-4.

19 Schotte DE, Stunkard AJ. Bulimia vs bulimic behaviors on a college campus. FAMA 1987; 258:1213-5.

20 Johnson-Sabine E, Wood K, Patton G, Mann A, Wakeling A. Abnormal eating attitudes in London schoolgirls - a prospective epidemiological study: factors associated with abnormal response on schoolgirls-a prospective epidemiological study: factors
screening questionnaires. Psychol Med 1988;18:615-22.

21 Fairburn CG, Beglin SJ. The studies of the epidemiology of bulimia nervosa. Am $\mathcal{F}$ Psychiatry (in press).

22 Drewnowski A, Yee DK, Krahn DD. Bulimia in college women: incidence and recovery rates. $A m$ f Psychiatry 1988;145:753-5.

23 King $M B$. Eating disorders in a general practice population. Prevalence, characteristics and followup at 12 to 18 months. Psychol Med 1989; Monograph Suppl 14:1-34.

24 Striegel-Moore RH, Silberstein LR, Frensch P, Rodin J. A prospective study of disordered eating among college students. International fournal of Eating Disorders 1989;8:499-510.

25 Freeman CPL, Munro JKM. Drug and group treatments for bulimia/bulimia nervosa. $\mathcal{F}$ Psychosom Res 1988;32:647-60).

26 Agras WS, McCann U. The efficacy and role of antidepressants in the treatment of bulimia nervosa. Annals of Behavioral Medicine 1987;9:18-22.

27 Hughes PL, Wells LA, Cunningham CJ, Ilstrup DM. Treating bulimia with desipramine: a double-blind, placebo-controlled study. Arch Gen Psychiatry 1986;43:182-6.

28 Walsh BT, Gladis M, Roose SP, Stewart JW, Stetner F, Glassman AH. Phenelzine vs placebo in 50 Walsh BT, Gladis M, Roose SP, Stewart JW, Stetner F, Glass
patients with bulimia. Arch Gen Psychiatry 1988;45:471-5.

29 Rossiter EM, Agras WS, Losch M. Changes in self-reported food intake in bulimics as a consequence of anti-depressant treatment. International fournal of Eating Disorders 1988;7:77983

30 Mitchell JE, Fletcher L, Pyle RL, Eckert ED, Hatsukami DK, Pomeroy C. The impact of treatment on meal patterns in patients with bulimia nervosa. International fournal of Eating Disorders 1989;8:167-72.

31 Pope HG, Hudson JI, Jonas JM, Yurgelun-Todd D. Antidepressant treatment of bulimia: a twoyear follow-up study. $\mathcal{F}$ Clin Psychopharmacol 1985;5:320-7.

32 Fairburn CG. A cognitive behavioural approach to the management of bulimia. Psychol Med 1981;11:707-11.

33 Wilson GT, Smith D. Cognitive-behavioral treatment of bulimia nervosa. Annals of Behazioral Medicine 1987;9:12-7.

34 Fairburn CG. The current status of the psychological treatments for bulimia nervosa. I Psychosom Res 1988:32:635-45.

35 Wilson GT, Rossiter E, Kleifield EI, Lindholm L. Cognitive-behavioral treatment of bulimia nervosa: a controlled evaluation. Behuv Res Ther 1986;24:277-88.

36 Fairburn CG, Kirk J, O'Connor M, Cooper PJ. A comparison of two psychological treatments for Fairburn CG, Kirk J, O'Connor M, Cooper PJ. A comp
bulimia nervosa. Behav Res Ther 1986;24:629-43.

37 Mitchell JE, Pyle RL, Eckert ED, Hatsukami D, Pomeroy C, Zimmerman R. A comparison study of antidepressants and intensive structured group psychotherapy in the treatment of bulimia nervosa. Arch Gen Psychiaury (in press). 
38 Garner DM, Bemis KM. A cognitive-behavioral approach to anorexia nervosa. Cognitive Therapy and Research 1982;6:123-50.

39 Garner DM, Bemis KM. A cognitive-behavioral approach to anorexia nervosa. In: Garner DM Garfinkel PE, eds. Handbook of psvchotherapy for anorexia nervosu and bulimia. New York: Guilford, 1985:107-46.
40 Cooper Z, Fairburn CG. The eating disorder examination: a semi-structured interview for the assessment of the specific psychopathology of eating disorders. International foumal of Eating Disorders 1987;6:1-8.

41 Cooper Z, Cooper PJ, Fairburn CG. The validity of the eating disorder examination and its subscales. Br f Psychiatry 1989;154:807-12.

\section{Community care}

\section{Research studies are essential}

Over the next decade the organisation and delivery of health care in the community will present the National Health Service with one of its most demanding tasks. If it is to succeed then studies and demonstration projects will need to be organised and carried out in all parts of the country.

The 1990s will see growing demands for comprehensive care and support of elderly, mentally ill, mentally handicapped, and physically disabled people either in their own homes or in residential accommodation in the community. A change is unavoidable-partly because of the increasing numbers of very elderly people ${ }^{1}$ and partly because of the fall in the number of school leavers, from whom the NHS recruits most of its staff. ${ }^{2}$ Only within the community are to be found the involuntary and voluntary carers and helpers needed to supplement scarce statutory services.

In November last year, the government published its long awaited proposals for community care. ${ }^{3}$ The white paper contained welcome emphasis on enabling people to live in their own homes, support for carers, proper assessment of need and good case management; and a real attempt to abolish current confusion and to clarify the responsibilities of agencies. Certainly it will help to remove several uncertainties and allow planning to proceed. No one, however, should minimise the task facing those authorities in making effective arrangements for delivering the services. ${ }^{+}$

There will still be an enormous array of agencies and staff with separate responsibilities and different loyalties. These include local social services, housing, and education; health authorities; family practitioner committees; general practitioners, both budget and non-budget holding; and nurses working for health authorities, general practitioners, hospitals providing outreach services, voluntary services, and residential and nursing homes. They will have to collaborate to ensure the best use of resources and the effective delivery of suitably integrated services.

Those in need of care also have to be identified. Their problems and capabilities must be assessed and progress predicted; and the frail elderly, those with chronic degenerative disorders, and many others will need regular reassessment. Welding together the various agencies and disciplines to reach joint decisions and to collaborate in exercising their responsibilities will require managerial skill and diplomacy. And this will be against local backgrounds of immense diversity in terms of geography, demography, and the ways in which services have been organised and developed.

Health and local authorities face two main tasks. Firstly, they will need to establish new management structures and mechanisms for coordinating the work of the agencies providing (or purchasing) and delivering services. These will need to be monitored, evaluated, amended, and developed. This will be achieved only with the help of research, underpinned by information systems. A recent innovative study in Newcastle upon Tyne examined the provision of care for physically handicapped and frail elderly people in the community, identifying the various relations between agencies and staff. ${ }^{6}$ The study team concluded that even in a city with excellent and well coordinated services the problems were sufficiently complex that responsibility should be devolved to a new, free standing, publicly accountable consortium formed by the health authority and the city council. Such a scheme might be regarded as at one end of a spectrum of options open to authorities in the light of the white papers on the health service ${ }^{7}$ and on community care. ${ }^{3}$ Another different and simpler approach adopted by some district health authorities in trying to unify services has been to introduce "advocates," whose role is to secure services and coordinate their delivery directly on behalf of individual clients. $^{8}$

The second main requirement is to develop outcome measures in community care, which at present are seriously deficient; among these must be assessment of the quality of life and patient satisfaction. Only in this way can the effectiveness of services be assessed.

If we are to achieve soundly based developments in community care - bearing in mind the wide local diversities the prime requirement is for district health authorities and local social service authorities to conduct studies and experiments. Such studies must flourish independently of priorities determined regionally or centrally. The authorities must be encouraged and helped, and in particular they must allocate or obtain sufficient finances to fund research. Such studies may be undertaken by their own staff, by academic departments, or by management consultants. There will be problems (in care and service delivery, for example) that are better examined on a multidistrict or regional basis, so a regional research capability will still be needed. And there will be problems with multiregional or national dimensions. Because government departments must respond to the requirements of ministers, the final tier needed may be an independent authority on the lines recommended by the Lords Select Committee ${ }^{9}$ or an institute of health as recommended by Sir Kenneth Stowe. ${ }^{10}$ Though the government's response to the former is less than encouraging. ${ }^{11}$

We should, then, expect to see a growth of monitoring of developments, exchange of information, and dissemination of good practice. But the most urgent need is to ensure that the authorities directly concerned with the development and delivery of local services can command studies and research into their own locally defined problems. This poses a particular challenge for public health doctors. A second pressing need is a much closer relation between the health service, academic departments, and funding agencies to develop research methods and measures and to train researchers.

Secretary,

Nuffield Provincial Hospitals Trust,

London NW1 7SP 